\title{
Rural B-Learning Contexts to Support the Physics Area - An Academic Performance Analysis*
}

\author{
Fabinton Sotelo Gomez** \\ Mario Solarte $e^{* * *}$ \\ Gustavo Ramirez González ${ }^{* * *}$
}

Received: 28/10/2019 - Accepted: 28/05/2020

https://doi.org/10.22395/rium.v20n38a12

\begin{abstract}
In this work, the academic performance of a tenth-grade physics course of high school is analyzed over three consecutive years, a b-learning educational context is configured in a rural area based on a framework that integrates Open Educational Resources (OER) to a Learning Management System (LMS). The performance of students who used b-learning is compared to other groups that received the same classes in a traditional way.
\end{abstract}

Keywords: high school, b-learning, physical area, dotLRN, educational web resources.

Paper Type: Research (Paper in extended version of the Seminario en Innovaciones Educativas SINNEM. Oct $18^{\text {th }}$, 2018). This research is funded by the grant of InnovAción Cauca 04-2017 for the PhD in Telematics Engineering from the University of Cauca, Popayan, Colombia, and Fundación Universitaria de Popayan (Popayan's University Foundation).

** Ph. D. candidate. Master. Intelligent Management Systems (IMS), Fundación Universitaria de Popayán, Colombia. E-mail: fabinton.sotelo@unicauca.edu.co. Orcid: 0000-0001-9274-8371

*** Ph. D. Telematics Engineering Group, University of Cauca, Popayán, Colombia. E-mail: msolarte@unicauca. edu.co. Orcid: 0000-0002-3600-7592

**** Ph. D. Telematics Engineering Group, University of Cauca, Popayán, Colombia. E-mail: gramirez@unicauca. edu.co. Orcid: 0000-0002-1338-8820 


\title{
Contextos B-learning rurales para soportar el área de física - Análisis de rendimiento académico
}

\begin{abstract}
Resumen
En este trabajo se analiza el desempeño académico de un curso de física de décimo grado de bachillerato durante tres años consecutivos, se configura un contexto educativo de B-learning en una zona rural a partir de un framework que integra recursos educativos abiertos (REA) a un Sistema gestor de Aprendizaje. El desempeño de los estudiantes que utilizaron el B-learning se compara con otros grupos que recibieron las mismas clases de forma tradicional.
\end{abstract}

Palabras clave: colegio, educación media, aprendizaje combinado, área de física, dotLRN, recursos educativos abiertos. 


\section{INTRODUCTION}

A LMS is a software with tools for the learning processes, it can be used in the classroom, virtual education and B-learning (blended-learning) [1]. Thus, in B-learning the teacher supports the learning process with Information and communications technology (ICT) [2]. There are a wide number of LMS platforms, among them, Moodle and dotLRN [3], [4], [5] are most widely used in the Open-Source world. Although, the platform depends on the needs of each institution [6], DotLRN offers advantages given its architecture and business approach [7], [8], [9]. One of the reasons that slows the use of LMS is the generation of the educational content. In this context, the integration of existing web resources (IWS) within a LMS offers many advantages: i) IWS allows the free use of a large amount of content available online, ii) IWS increases the quantity and quality of educational content since it opens the possibility to view videos, images, text, etc., iii) IWS reduces the distraction of students, given that if resources are integrated into the LMS, it is not necessary to leave the platform to access the internet. The latter promotes student concentration and time efficiency. Although it is possible to find different works on the integration of web resources as educational services in LMS, few studies have been proposed to address the integration in dotLRN. This integration poses great challenges due to the particularities of the architecture and the programming language of dotLRN. This problem has been recently addressed and the partial results are documented in [10], where a detailed review of existing approaches is presented. Also in [11], [12], and [13], a framework to incorporate Web resources in dotLRN is described. The framework includes some architectural and integration guidelines to integrate web resources in dotLRN. The guidelines enable teachers to reuse materials from the web.

This paper analyzes the results of three case studies, [11], [12] and [13], in a blearning physics course that used the framework to integrate educational web resources. In order to evaluate the efficiency of the use of the framework for case studies, the performance of the groups using b-learning was compared with groups supported in the conventional way. The sections of the article are: 2) description of the frame of reference; 3) case study; 4) results and 5) conclusions.

\section{FRAMEWORK TO INTEGRATE WEB RESOURCES TO DOTLRN}

LRN has many advantages, some of these are detailed in [7]; dotLRN aims at facilitating the e-learning processes from registration, documents sharing, and users management. Besides, dotLRN LMS offers many tools to interact with external resources opening the door to interaction with other LMS and Web resources as in [3]. The framework for the integration of web resources such as e-learning services in dotLRN is described in [12]. The integration framework defines the requirements and architectural guidelines 
for integrating web resources within dotLRN. A web resource can be defined as an element identified by a URI (Uniform Resource Identifier), hosted online and accessed using a version of the HTTP protocol according to the ISBD ER (Standard International Bibliographic Description) and W3C (World Wide Web Consortium). Some examples of e-learning services are Google Docs or Google Forms or other Web 2.0 as a platform for educational activities [14]. Most of the web resources are accessed using the HTTP protocol. This feature allows interacting with different technologies such as Flash, Java, Javascript, Html5, Web 2.0, etc. Due to the fact that many educational resources based on HTTP can be found, it is necessary to set minimum requirements to ensure integration with dotLRN. During a course, a teacher may need to include services that are not present in the LMS. DotLRN solves this need by using applets, portlets, and packages. For this reason, the integration of web resources in dotLRN is based on these three elements: 1. Package: contains the data model, the logic and the operation of the package. Likewise, it integrates the user interface of the package. During the integration, in this element, the programming is done to reference the URL of the web resource. 2. Portlet: provides the user interface for the portals of the platform. In this element, the graphical interface of the package and its management is defined describing the web resource linked to the package. 3: Applet: uses the interface of the portlets and set the properties for the dotLRN portal. This function allows administrators and teachers to add applications to the course. The requirements to ensure the integration of web resources dotLRN are the following: 1) resources must be identified by a URL; 2) the whole web site to which the resource belongs shouldn't be integrated; 3) the displaying size of the resource must be considered. The resource must be incorporated into the web site dotLRN, and limited space is available; 4) extra features (flash, java, javascript, html5, web 2.0, etc.) must meet the above requirements; 5) web browsers must support the necessary plugins to run web resources and 6) the web resources must provide learning functionalities to the dotLRN course.

The guidelines to be followed for the integration of web resources that provide e-learning services in dotLRN are the following: 1) create the package using the Package Manager; 2) program the package to reference the web resource to integrate; 3) create portlet directories and applet. This task is done automatically using the Nima Mazloumi script; 4) set the portlet to describe the web resource and link to the package; 5) set the applet only if necessary; 6) install the applet and the portlet through the installation tool dotLRN software; Finally, 7) the application is available to be added in a course from the option "Manage applets".

\section{CASE STUDY}

For the case study, the Jose Maria Cordoba (Jomaco) high school in the rural area of Cauca was selected. Jomaco is a public educational institution, located in Mondomo, 
$60 \mathrm{~km}$ from the Cauca capital, Popayan. It has approximately 600 students from sixth to eleventh grade. In each case an educational process was carried out in the course of physics in wave, electricity and basic electronic topics for the tenth grade, for which four educational web resources were evaluated. For the evaluation purposes of this paper, 100 students in b-learning mode and 100 outside this modality, took an evaluation of the topics seen in the platform to perform an academic performance analysis. Table 1 shows the verification of the requirements to integrate the services, since it is the first thing that must be done to comply with the framework:

Table 1: verification of web resource requirements, (Yes/No)

\begin{tabular}{|c|c|c|c|c|c|c|c|}
\hline \multirow{2}{*}{$\#$} & \multirow{2}{*}{ Criteria integration } & \multicolumn{6}{|c|}{ Web resources } \\
\hline & & 1 & 2 & 3 & 4 & 5 & 6 \\
\hline 1 & The resource has a URL & $\mathrm{Y}$ & $\mathrm{Y}$ & $\mathrm{Y}$ & $Y$ & $\mathrm{Y}$ & $\mathrm{Y}$ \\
\hline 2 & Identification of the URL of the resource & Y & Y & Y & Y & Y & Y \\
\hline 3 & Display size checked & Y & Y & Y & Y & Y & Y \\
\hline 4 & Compatible functionality with HTTP & Y & Y & Y & Y & Y & Y \\
\hline 5 & Compatibility with most browsers & Y & Y & Y & Y & Y & Y \\
\hline 6 & The resource supports a learning process & Y & Y & Y & Y & Y & Y \\
\hline
\end{tabular}

The following steps were performed according to the guidelines described by the framework: 1: create the package Fisica using the Package Manager. Google Maps will be integrated in the platform; 2: configure the package to reference the web resources according to the integration guidelines; 3 : create directories for the portlet and the applet. The directories of the portlet and the ones generated by the script are copied to the package's directory of dotLRN (/usr/share/dotlrn/packages), the package directory has three application directories (fisica, fisica-portlet and dotLRNfisica); 4: set the portlet to describe the web resource, link it to the package and develop its administration; 5: set the applet only if necessary, in this case it is not necessary since the generated applet meets the requirements of the portlet; 6 : install the applet and the portlet using the installing tool in dotLRN with the option Installfrom Local ->Service -> selection of the applet fisica; 7: finally, the application is available to be added in the course in the option 'Manage applets' in the Admin portal of the course. After an implementation of the software (dotLRN) in the hardware (server), its verification is necessary using the client access (teacher and student). The six web resources integrated into the case study are simulators. The students can interact to strengthen their knowledge regarding concepts of electric current, voltage, resistance, tension, damping oscillation pulse amplitude, among others, the figures 1 to 6 show the web resources integrated to dotLRN.

Web resources integrated to dotLRN, thematics: Electricity Waves and Basic electronic: 
190 Fabinton Sotelo Gomez, Mario Solarte y Gustavo Ramirez González

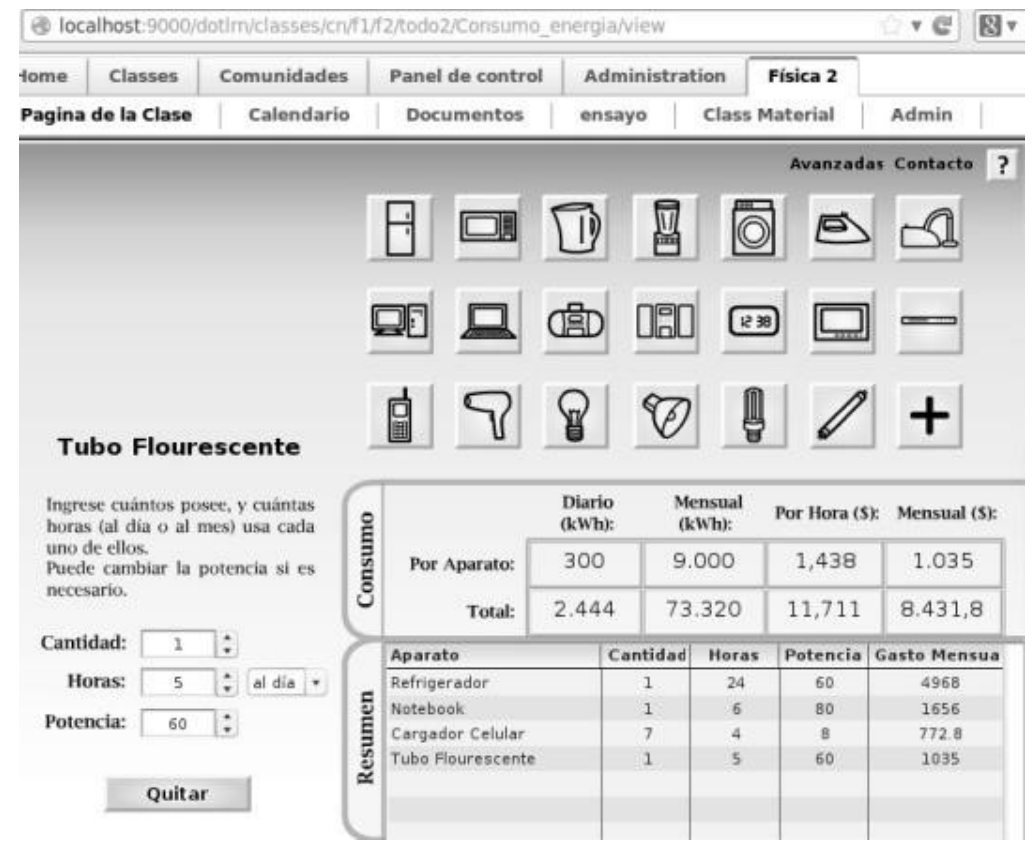

Figure 1. Web resource 1, thematic: Electricity

Source: own elaboration.

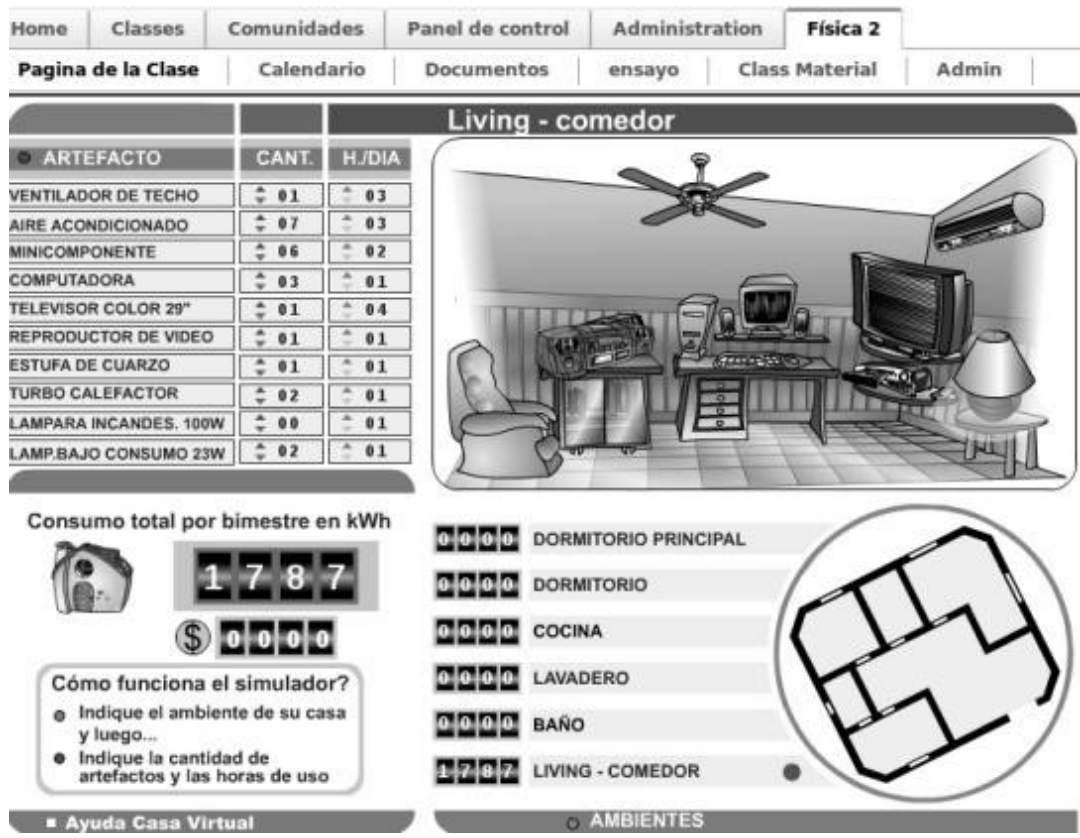

Figure 2. Web resource 1, thematic: Electricity

Source: own elaboration. 
Rural B-Learning Contexts to Support the Physics Area - An Academic Performance Analysis 191

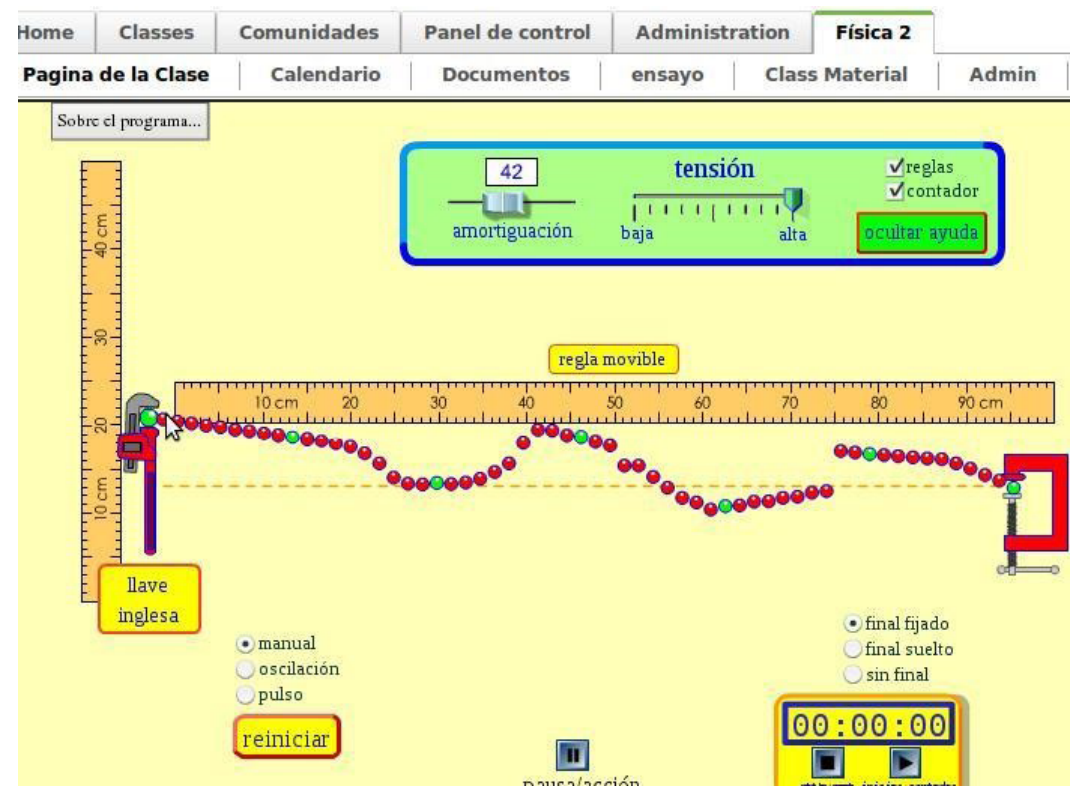

Figure 3. Web resource 3, thematic: Waves

Source: own elaboration.

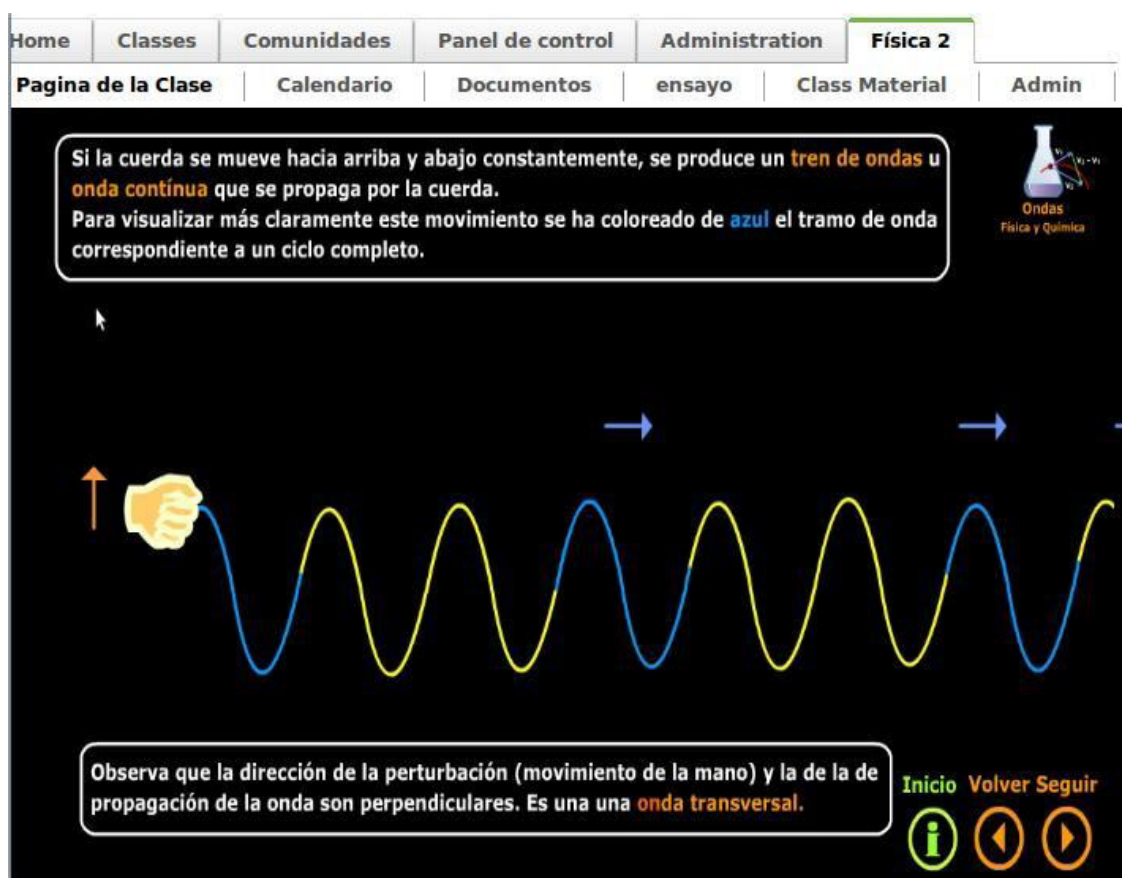

Figure 4. Web resource 3, thematic: Waves

Source: own elaboration.

Revista Ingenierías Universidad de Medellin, 20(38) • Enero-Junio de 2021 • pp. 185-198 • ISSN (en línea): 2248-4094 


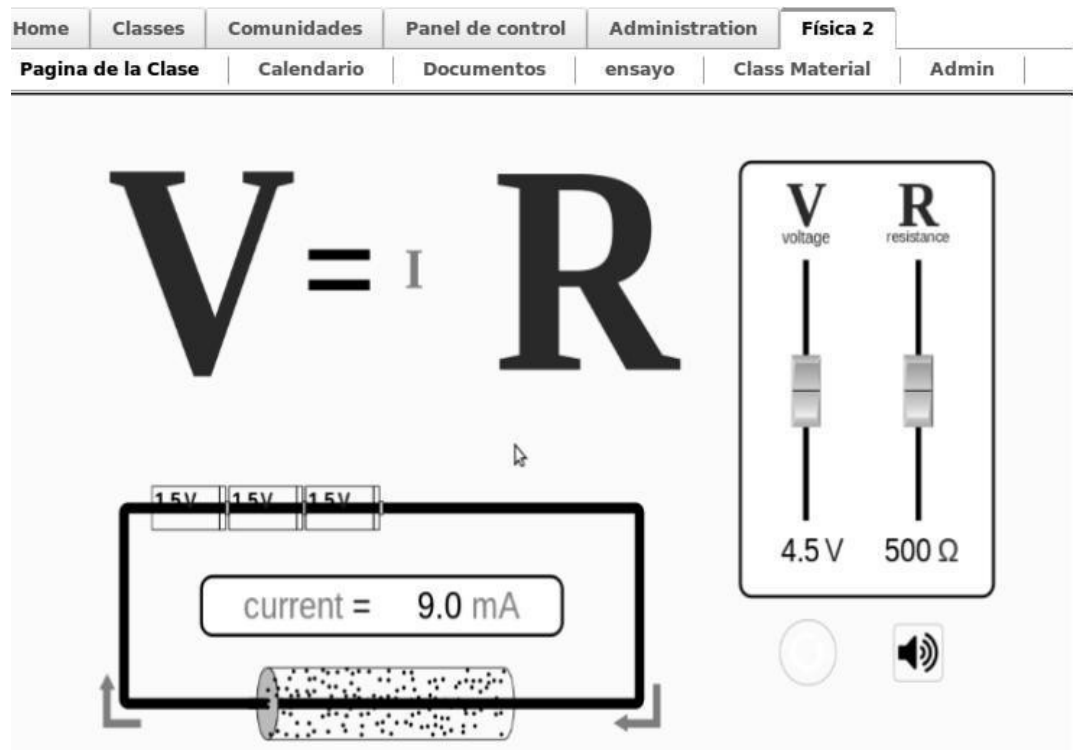

Figure 5. Web resource 5, thematic: Basic electronic Source: own elaboration.

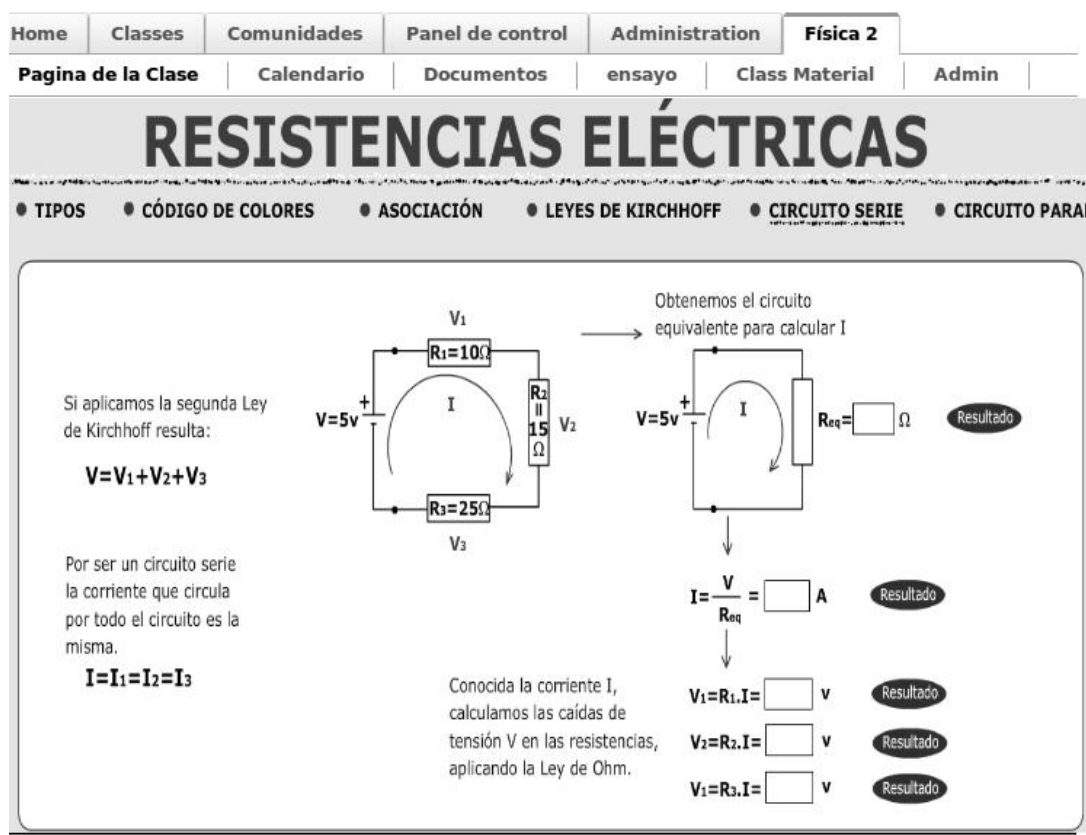

Figure 6. Web resource 5, thematic: Basic electronic

Source: own elaboration. 


\section{Implementation of the b-learning process}

The number of students whose academic performance was analyzed is 200 , in the tenth grade, of three different years (2013, 2014 and 2015). Each year was distributed as follows: 35 students were guided in B-learning mode (Group A) and the other 35 were guided using traditional methods (Group B). The evaluation was done to compare the academic performance and verify the impact of the use of web resources during the student learning process. This process is done by working sessions of the research team, faculty members, administrators, and students.

Day 1: Management of the platform: With the teacher: some details about the platform and the web resources were described. Equally, a basic training about dotLRN was oriented. The elements covered were: access to the platform, registration, login and available courses. Likewise, the basic elements of courses were explained: activities, forums, materials, assessments, calendar, email, students and integration of educational web resources by aggregating applets. With the students: training is done to register on the platform, access and interact with the courses and web resources. Likewise, some training was carried out on forums and online questionnaires.

Day 2: Definition of the teaching methodology: the methodology to be applied to Group A is defined. It was intended that the methodology was close to the methodology used in the classroom on a daily basis, in this way the research group and the teacher agree on the following methodology: The platform course is named with the grade and subject to which it is applied: Física_Decimo. The teacher explains the theory of the subject in a conventional manner (board, projector, exposition, and interaction with the student). In the virtual course the courses and web resources are integrated. These contain textual, multimedia, and practical information that simulates an interactive process with the student. A reasonable time is given to the student to interact with the resources. These resources support the conventional educational process. A forum activity is proposed on the platform. The teacher proposes a workshop with a series of questions on the subject. This workshop is solved with the help of educational resources. The teacher reviews the workshops, socializes them and clears up doubts. An examination activity is implemented as assessment. This evaluation is based on evidence-based know 11 (knowledge measurement system applied by the Colombian Ministry of Education). The assessment questions have single or multiple answers. Finally, the results of the evaluation are analyzed and compared with students who did not receive the b-learning method.

Day 3: Application of the proposed methodology: The class was developed during 3 hours in the computer room, where each one of the 35 students has a computer connected to the LMS. Relevant observations in the class regarding the students: 
Greater attention, concentration, interaction, less indiscipline, greater participation, a fluent handling of the platform and its necessary modules (e-learning resource, forum, evaluation) is observed. Students were enthusiastic about the two simulators; they mentioned that the topic is clear and the resources helped to clear up doubts. Relevant classroom observations regarding the teacher: from the responses in the forum, the teacher observed that the students were more efficient, fast and motivated. The 35 students developed the workshop correctly. The teacher expressed: "optimizing the understanding of students is very important; assessments through forums allows us to know the learning process of each student and his motivation. The results are satisfactory compared to those obtained in a conventional manner". At the end of the day, a survey was applied to students to determine the satisfaction and efficiency of the approach. $100 \%$ of the students liked to use the computer in the learning process. $90 \%$ considered it easy to enter to the platform. $100 \%$ considered easy to find the resource suggested by the teacher; this issue avoids distraction and greater concentration. $80 \%$ considered it easy to integrate the LMS service. $100 \%$ understood the topic. $100 \%$ would like all teachers to use this tool in their classes. $85 \%$ considered as excellent the employment of ICTs in education and recognize the need for more computers and a higher bandwidth.

\section{RESULTS}

This section describes the results obtained in the case study. The following tasks were accomplished: platform installation, creation of student and teacher users; integration of six web resources, no performance or technical platform setbacks, good management of the platform by students and teachers for each one of the functions needed. On the other hand, an impact analysis in academic performance with the teachers involved in the two subjects was performed in the fourth day.

Day 4. Assessments analysis: table 2 shows the number of students in a classification of three ranks according to their results in the evaluation of the respective topic (thematic) in a rating scale from 1 to 5 as follows: low: 1.0 to 3.0; basic: 3.1 to 4.4; high: 4.5 to 5.0 .

Table 2. Students assessment analysis by thematic and year

\begin{tabular}{cccccccccc}
\hline & \multicolumn{8}{c}{ Number of students in evaluation range } \\
\cline { 2 - 11 } Group & \multicolumn{3}{c}{ Year 2013, Electricity } & \multicolumn{3}{c}{ Year 2014, Waves } & \multicolumn{2}{c}{ Year 2015, Electronic } \\
\cline { 2 - 11 } & Low & Basic & High & Low & Basic & High & Low & Basic & High \\
\hline A & 3 & 8 & 24 & 5 & 7 & 23 & 2 & 6 & 22 \\
B & 10 & 15 & 10 & 12 & 16 & 7 & 8 & 12 & 10 \\
\hline & \multicolumn{8}{c}{ Source: own elaboration }
\end{tabular}


The percentage results of the student assessment groups A (b-learning) and B (conventional classes) of the years 2013, 2014 and 2015 are shown in table 3.

Table 3. Students assessment analysis by thematic and year

\begin{tabular}{ccccccccccc}
\hline & \multicolumn{9}{c}{ Percentage performance analysis (\%) } \\
\cline { 2 - 11 } Group & \multicolumn{3}{c}{ Year 2013, Electricity } & \multicolumn{3}{c}{ Year 2014, Waves } & \multicolumn{3}{c}{ Year 2015, Electronic } \\
\cline { 2 - 10 } & Low & Basic & High & Low & Basic & High & Low & Basic & High \\
\hline A & 8.6 & 22.9 & 68.6 & 14.3 & 20.0 & 65.7 & 6.7 & 20.0 & 73.3 \\
B & 28.6 & 42.9 & 28.6 & 34.3 & 45.7 & 20.0 & 26.7 & 40.0 & 33.3 \\
\hline \multicolumn{9}{c}{ Source: own elaboration. }
\end{tabular}

Rating Scale: 1 to 5: low: 1.0 to 3.0; basic: 3.1 to 4.4; high: 4.5 to 5.0.

Table 4 shows a percentage analysis where the academic performance is measured in the three topics applied in the three years of the case study, taking into account the low, basic and high performance scale. In figure 7 the analysis of the above table is plotted.

Table 4. Average percentage of academic performance of the three thematic

\begin{tabular}{cccc}
\hline \multirow{2}{*}{ Group } & \multicolumn{3}{c}{ Grading scale (\%) } \\
\cline { 2 - 4 } & Low & Basic & High \\
\hline A & 9.8 & 21.0 & 69.2 \\
B & 29.8 & 42.9 & 27.3 \\
\hline
\end{tabular}

Source: own elaboration.

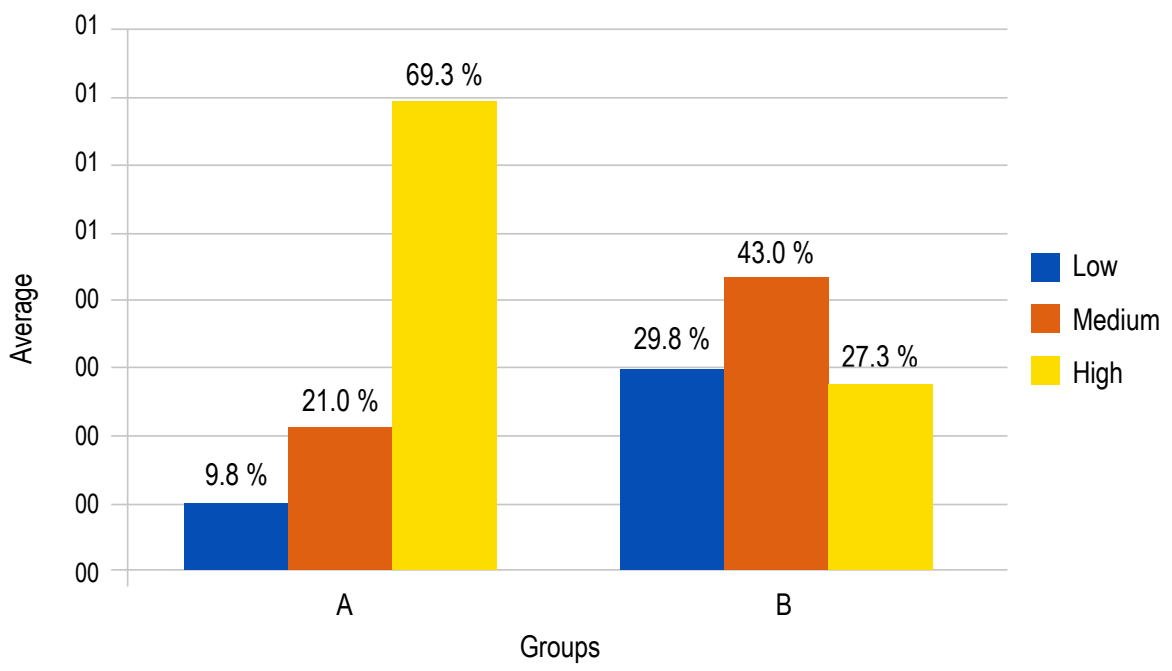

Figure 7. Average percentage of academic performance

Source: own elaboration. 
Table 5 shows the percentage average of the number of students who approved and disapproved the evaluation of the three topics in their respective group.

Table 5. Average percentage of approval and disapproval of the three topics (\%)

\begin{tabular}{ccc}
\hline Group & Approval & Disapproval \\
\hline A & 90.3 & 9.8 \\
B & 70.3 & 29.8 \\
\hline \multicolumn{3}{c}{ Source: own elaboration. }
\end{tabular}

Figure 8 shows graphically the percentage analysis of the result obtained after evaluating group $\mathrm{A}$ and $\mathrm{B}$ of students, who approved and disapproved

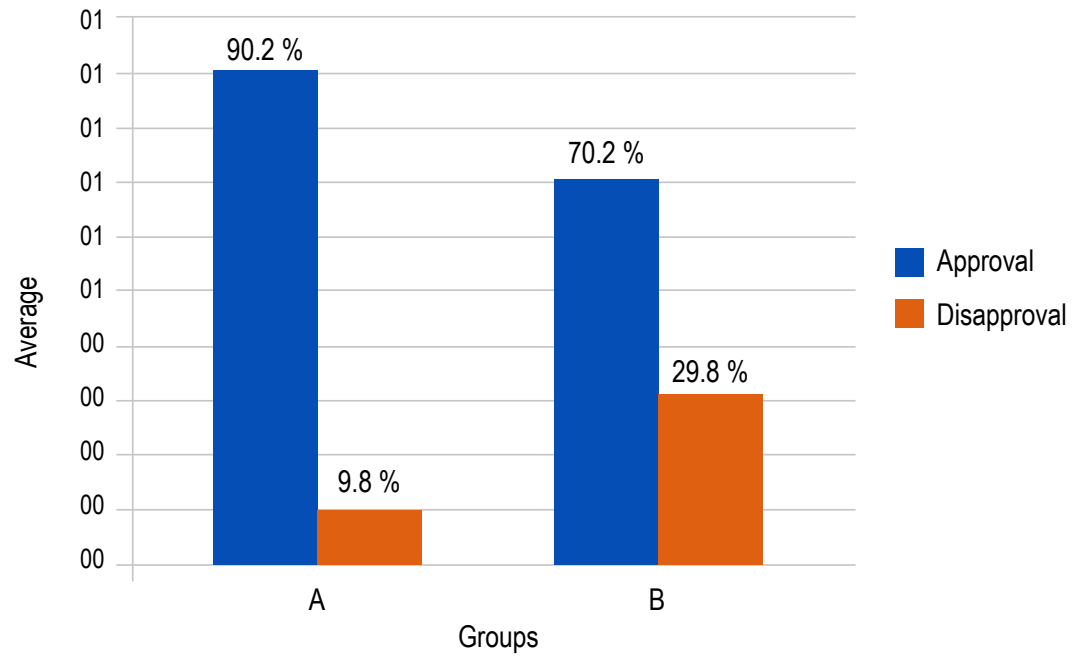

Figure 8. Average percentage of approval and disapproval

Source: own elaboration.

Performance Analysis: In general terms, 200 students were analyzed divided into two groups. Group A used the LMS and group B didn't use the LMS. In group A, only $9.8 \%$ achieved low performance vs. $21.2 \%$ in group B. In group A $69.5 \%$ of students reached a high performance while in group B only $27.3 \%$. Regarding the percentage of students who approved and disapproved: In group A $90.3 \%$ passed the assessment while in group B only $70.3 \%$. In group A only $9.8 \%$ did not approve the assessment while in group B the percentage was 29.8 . In differential terms it can be evidenced that the group that used the b-learning context obtains $42 \%$ more students in the high-performance range and $20.0 \%$ less in low performance. 


\section{CONCLUSION AND FUTURE WORK}

With the implementation of the proposed framework in the physics course of the tenth grade it was possible to demonstrate that: the proposed framework, which integrates the web resources, has been well received by the educational community. The students who used the platform achieved a better performance in comparison with the group that received conventional instruction. With the integration of resources a greater concentration of students can be achieved since the teachers do not see themselves in the need to leave the platform to make use of them. This helps them not to scatter and navigate on distracting websites. The framework for integrating external services in dotLRN allows reusing more and better resources in the platform, thus supporting educational processes. Future work includes the evaluation of the framework with other services and LMS such as Moodle. Likewise, the implementation of these resources is envisaged in other educational institutions with different types of communities, such as indigenous, Afro-Colombian and urban ones.

\section{ACKNOWLEDGEMENTS}

This paper received support of the research groups Intelligent Management Systems (Fundación Universitaria de Popayán), Telematics Engineering Group of the University of Cauca and was co-financed by InnovAcción Cauca.

\section{REFERENCES}

[1] J. M. Boneu, "Plataformas abiertas de e-learning para el soporte de contenidos educativos abiertos," RUSC. Univ. Knowl. Soc. J., vol. 4, no. 1, pp. 36-47, 2007.

[2] J. C. Almenara, "Bases pedagógicas del e-learning," RUSC. Univ. Knowl. Soc. J., vol. 3, no. 1, p. $0,2006$.

[3] LRN Consortium, “DotLRN.” http://dotlrn.org/about/ (accessed Apr. 06, 2021).

[4] LRN Consortium, “Openacs.” http://dotlrn.org/about/openacs/ (accessed Apr. 06, 2021).

[5] L. Martin, D. R. Martínez, O. Revilla, M. J. Aguilar, O. C. Santos, and J. G. Boticario, "Usability in e-Learning Platforms: heuristics comparison between Moodle, Sakai and dotLRN," 2008.

[6] J. C. G. Mariño, "B-Learning utilizando software libre, una alternativa viable en Educación Superior," Rev. Complut. Educ., vol. 17, no. 1, p. 121, 2006.

[7] S. Martín, M. Castro, R. Gil, and J. Peire, "Interoperability between the new open e-learning platforms: an intelligent answering machine," Univ. Nac. Educ. a Distancia España, 2007. 
[8] E. San Cristóbal, "Metodología, estructura y desarrollo de interfaces intermedias para la conexión de laboratorios remotos y virtuales a plataformas educativas," Tesis Dr. Univ. Nac. Educ. A Distancia, España, 2010.

[9] O. C. Santos, J. G. Boticario, E. Raffenne, and R. Pastor, "Why using dotLRN? UNED use cases," in Proceedings of the Floss (Free/Libre/Open Source Systems) International Conference, 2007, pp. 195-212.

[10] F. Sotelo Gomez and A. Ordóñez, “Aplicación del marco de referencia para la integración de recursos web en Dotlrn en la asignatura de Física - Temática Electricidad," Nuevas Ideas en Informática Educ. TISE 2015, p. 6, 2015, [Online]. Available: http://www.tise.cl/volumen11/ TISE2015/724-729.pdf.

[11] F. Sotelo Gomez and M. F. Solarte, "Incorporación de recursos web como servicios de e-learning al sistema de gestión de aprendizaje. LRN: una revisión,” Tecnura, vol. 18, no. 39, pp. 165-180, 2014.

[12] F. Sotelo Gomez and M. F. Solarte, "Marco de referencia para la integración de recursos web como servicios de e-learning en. LRN," 2013.

[13] F. Sotelo Gomez and A. Ordóñez, "Application of a Reference Framework for Integration of Web Resources in Dotlrn-Case Study of Physics-Topic: Waves," Int. Assoc. Dev. Inf. Soc., 2016.

[14] W3C, "Web Characterization Terminology \& Definitions Sheet.” https://www.w3.org/1999/05/ WCA-terms/\#Resource (accessed Apr. 06, 2021). 